\title{
The Experiences of Young Liver Patients Transferring From Children's to Adult Services and Their Support Needs for a Successful Transition
}

\author{
Alex Toft, PhD, Rachel Taylor, $\mathrm{PhD}^{2}$, Lee Claridge, BM, BS (Hons) ${ }^{3}$, Charlotte Clowes ${ }^{1}$, \\ James Ferguson, FRCPE, MD ${ }^{4}$, Jonathon Hind, FRCPCH ${ }^{5}$, Rebecca Jones, FRCP, $\mathrm{PhD}^{3}$, \\ Patricia McClean, FRCPCH, MD ${ }^{3}$, Patrick McKiernan, $\mathrm{FRCPCH}^{6}$, Marianne Samyn, \\ $\mathrm{FRCPCH}^{5}$, and Jane Coad, $\mathrm{PhD}^{1}$
}

\begin{abstract}
Background: The period of transition from pediatric to adult services represents a time when young people need support, information, and appropriate care in order to successfully move. It is a period that is associated with nonadherence and disengagement with care. Objective: To explore the experiences of young liver transplant recipients transitioning to adult services and determine what they require in order to achieve a successful move. The research also explored the possibility of using a mobile phone application (app) as a tool to support transition. Design: Qualitative approach using novel arts-based focus groups and one-to-one interviews. Participants: Twenty-one young people aged 16 to 25 years, 16 health-care professionals involved in their care, and 7 young people as follow-up. Participants used services provided by the 3 liver centers in England (Leeds, Birmingham, and London). Results: Data highlighted the variability of transition pathways in England for young people moving from child to adult health services. The results showed that they required clear information regarding transition processes including specific medical information and that there was a shortfall in such information. Support was required in the form of a designated transition coordinator or similar specialist who could act as a point of reference and guidance throughout the process. Transitions needed to be individualized and based upon transition readiness rather than age, although the research showed that age cut-offs were still used. Conclusion: Young people welcomed apps to provide information, reminders, contacts, and connections. Future research should explore the efficacy of such apps.
\end{abstract}

\section{Introduction}

The preparation and process of transferring from child to adult health-care services is often labelled as transitioning, a word which conjures images of a steady and organized flow into a new hospital under the care of new adult consultants. ${ }^{1}$ How- ever, in practice, transition is synonymous with increased anxiety surrounding care $^{2}$ and often coincides with a period in which young people stop taking their medication 3 , making transition a challenging period of young people, and their health-care providers. As young people transfer to adult services, they are required to take the lead in their care, shifting the emphasis away from their parents/carers.

When complete, the transfer to adult services should repre- sent a time when young people are able to self-manage their care. However, self-management is problematic and if plans are not put in place early by professionals, young people can disengage with the process. ${ }^{4}$

\footnotetext{
${ }^{1}$ Coventry University, Coventry, England, United Kingdom

${ }^{2}$ London South Bank University, London, United Kingdom

${ }^{3}$ Leeds Teaching Hospital, Leeds, England, United Kingdom

${ }^{4}$ Queen Elizabeth Hospital, Birmingham, England, United Kingdom ${ }^{5}$ Kings College Hospital London, London, England, United Kingdom ${ }^{6}$ Children's Hospital of Pittsburgh of UPMC, Pittsburgh, PA, USA
}

Corresponding Author:

Alex Toft, Centre for Innovative Research Across the Lifecourse (CIRAL), Coventry University, Richard Crossman Building (4th Floor), Priory Street, Coventry CV1 5FB, United Kingdom.

Email: ab7240@coventry.ac.uk 
for young people's long-term health, specifically with regard to medication adherence, ${ }^{3}$ knowledge of medical conditions that ultimately improve health management, ${ }^{4}$ and overall self- management of care where the young people fully engage with the services they access. ${ }^{5}$

It is now common for liver transplant recipients to survive into adulthood with 9 of the 10 transplanted livers continue to function for at least 1 year posttransplant, ${ }^{6}$ suggesting that more young people transition to adult services. Previous research has suggested that the process of transition needs to be standardized ${ }^{7}$ and includes key features such as dedicated transition specialists and planning, visits to adult hospitals prior to transfer, and familiarization with new professionals. ${ }^{8}$ In practice, the recent Ready Steady Go initiative has attempted to enshrine these concepts, ${ }^{9}$ although this is not mandated and there was no evidence in its use during the course of this research project. Previous research has explored the use of web-based tools ${ }^{2}$ and text-messaging services ${ }^{10}$ to help support transition, yet research exploring the use of phone applications remains limited.

This article aims to address 2 main objectives: (1) to explore what is needed in order to achieve a positive transition from young people's perspective and (2) to ascertain whether young people and professionals feel mobile phone technology (apps) can be a useful tool to support transition.

\section{Method}

\section{Design}

We conducted qualitative focus groups and interviews with young people (aged 16-25 years) who attended the 3 regional English liver centers (Leeds, Birmingham, and London). Pro- fessionals who worked with the young people were also inter- viewed. Twenty-one young people and 11 professionals participated in the research. Informed consent was obtained from all individual participants included in the research. Ethi- cal approval was obtained through National Health Service (NHS) proportional review, the project was also approved by Coventry University ethics.

\section{Population}

A total of 21 young people aged 16 to 25 years took part in the research: 3 focus group totaling 11 participants and 10 inter- views. Eleven professionals who worked with liver transplant recipients were interviewed by telephone and 5 professionals also took part in a focus group. Two follow-up focus groups were conducted with 7 young people. Participants had all accessed the 3 regional English liver centers (Leeds, Birming- ham, and London) or worked at such clinics (professionals). No other demographic data were collected.

\section{Sampling}

The research team consisted of academics and professionals working with young liver transplant recipients from the 3 regional English liver centers (Leeds, Birmingham, and Lon- don). Professionals approached and recruited young people who they saw professionally into the study. As such, all sampling was purposive with the professionals on the research team selecting who should take part in the research. In this instance, the professional had an established relationship, and this proved useful during focus groups to put participants at their ease. However, the participants had no prior knowledge of the interviewer during face-to-face interviews. Participants were given information sheets and corresponding consent forms to sign. Information sheets shared the purpose of the project, its goals and how data collection would take place. It was clear to the participants that the research was being conducted by the Children and Families Research team at Coventry University on behalf of Children's Liver Disease Foundation (CLDF). Due to a low response rate in 1 site, the funder CLDF advertised and recruited additional participants.

\section{Data Collection}


Data collection took the form of qualitative focus groups and telephone semistructured interviews. Both were guided by the same interview schedule to ensure consistency. Interview schedules were constructed guided by the study objectives, and the literature review to ensure questioning was focused and guided by previous research. The interview schedule had 3 main sections: (1) background questions exploring current care, levels of support, care plans, negative/positive experiences; (2) experiences of transition including questions on knowledge of the process, concerns, transition plans; (3) the use of technology to support transition to discover current technology usage, thoughts on phone applications, and what information/ support such an application should contain.

The focus group used traditional questioning but also arts- based methods which were open and accessible. This included drawing, the use of brainstorming and interactive activities such as using Target Boards (designed by authors J.C. and A.T.) upon which participants could place notes to show which aspects were more important than others. Focus groups took place in private meetings rooms/conference rooms in bowling alleys. This ensured that the venues were neutral but also allowed the young people and professionals to socialize and to feel relaxed. Focus groups were facilitated by the research team, and interviews were conducted by Toft (first author) to ensure consistency. Both the focus groups and telephone inter- views lasted for approximately 1 hour. No interviews/focus groups had to be repeated.

\section{Analysis}

Interviews/focus groups were audio recorded and transcribed verbatim. This allowed the research team to thematically analyze the stories presented by both young people and professionals. The thematic analysis used for the project took its guidance from the analysis practiced commonly in social research as described by Boyatzis. ${ }^{11}$ Principally, this method involves manually sifting through the transcription data and looking for common themes in relation to the problems posed. Data were then framed using the research questions and interpreted and understood at a deep level. As such, themes were derived from the data itself but given a framework using the aims of the data collection process. This thematic analysis was conducted by the primary author but verified and checked by the entire research team. Due to time restraints associated with the project, transcriptions were verified solely by the research team and not the participants.

\section{Results}

Five main themes emerged from the analysis: communication, knowledge and information, models of transition, self- management and ownership, and using mobile technology.

\section{Communication}

Young people were keen to highlight shortcomings in their transition experience, and throughout the results section these will be used to explore how to improve the transition process. Young people specifically highlighted the issue of communication between professionals as a potential pitfall which could threaten the transition process and their care in general. One participant noted that it was often difficult to ensure that their general practitioner (GP) communicated effectively with the hospital:

It's more from the GP communicating with the hospital rather than the other way round. The system I have is that I have quarterly blood tests that are faxed off to the [hospital] and once I went a whole year with them saying we've faxed off your blood tests and then turns out they'd never been faxed.

This breakdown of communication is further exacerbated by the fact that in adult services there is often no continuity with regard to which professionals young people see. One young person was concerned that this could lead to real difficulties if they suddenly became unwell.

I did request a while ago about maybe even seeing somebody who I had a relationship, even once a year to build up some sort of continuity and trust with somebody, because I have no relationship with any person now in adult services. It does worry me that should there be a time that I have to be back in hospital or I'm unwell, I don't have anybody who I have a real relationship with. I think continuity plays a huge part in things. 
As a result, young people wanted consistency in care with a strong focal point throughout the transition process. This role could be filled by a transition nurse/coordinator or any professional in a dedicated position who is visible to young people and known to be the point of contact with regard to transition. Several young people spoke of transition nurses/coordinators, suggesting that their role was vital and provided stability throughout their transition: "Yes, because firstly (transition nurse) is the easiest to get in touch with, I have her mobile number and she was there when I had my transplant so she's known my case and my family for a very long time and so I know her on a bit of a personal level..."

This was supported by the professionals who were inter- viewed, who highlighted the importance of this role, and the cross-site working that takes place:

Having [transition nurse] and [support worker] definitely works well. Having a designated nurse that works across both sites, that works really well. And there's a desperate need to be expanded - when it does work it works really well, but because of the pressure of service and only one nurse it's quite difficult to achieve it all.

Interestingly, one young person suggested that the relation- ship with the consultant was most important. For young people who receive transplants at an early age and remain with the same consultant for a considerable length of time, this relation- ship acted as the point of consistency. Pathways of communication needed to be clear, and professionals need to be accessible and known to young people.

\section{Knowledge and Information}

The young people highlighted a shortfall in knowledge about the transition process itself and relevant medical information. One young person noted that they had received good information about their health and medication, but this had not been replicated for the process of transferring to adult services.

I think the process really needs to be explained a lot more and that's why I think discussing it earlier and then having the opportunity to discuss it repeatedly to ask those questions that you don't really understand. I've always been quite comfortable asking questions, so I did have quite a good level of understanding about my medication and health.

Information available from professionals appears to be difficult to obtain with young people not knowing where to turn for assistance: "If I was coming up for an appointment, I'd ask my consultant but if not I'd probably ring CLDF to see if they can offer me anything."

This quotation suggested that beyond accessing the consultant, CLDF are the first point of reference for most liver patients. Importantly, this is also supported by a professional who referenced the information compiled by CLDF:

If there was somebody who was struggling with say adjustment we do tend to talk about their condition and I'd tend to signpost them to things like the CLDF website as they have really good interactive things where you can click on the liver, learn all about what it does and all the conditions so that would generally be my starting point.

It is clear that there is a deficit of accessible knowledge, or more accurately the knowledge exists but may not be known to those who do not access CLDF's services.

\section{Models of Transition}

Data suggest that young people needed to transfer to adult services when they were ready and not as a result of reaching a specific age (usually 16 or 18). Transition readiness appears to be a more effective measure for success than simply age. The following quotation represents a common feeling put forward by a number of the young people:

I felt like I'd been dumped over. My first appointment in adult services, my [Pediatric] consultant didn't come in it was just me and the adult consultant. I think the idea is that it's a transition but they just didn't get it right, it just felt like I'd been dumped in their lap." 
This quotation effectively summarizes the result of limited transition preparation (no visiting adult services/professionals prior to the transition). Professionals also felt that the practice of transferring based upon age, which still occurred, is problematic:

I do have concerns in that 16 is the age that they're transferred over regardless of what might be going on in their lives at that point and it might not be a good time to be transferred, whether medically or psychologically, or there might be something huge going on in their lives.

Some services have begun developing measurements and assessments to enable them to transition young people when they are ready rather than solely based upon their age. A good example was shown in 2 liver services who were working to develop the HEADSS (home, education/employment, peer group activities, drugs, sexuality, and suicide/depression) assessment, ${ }^{12}$ a psychological evaluation tool for young people. The HEADSS assessment aims to understand the emotional well-being of the young person on a much deeper level. One interviewed professional noted: "We're hoping that will get better with the Ready Steady $\mathrm{Go}^{9}$ and then every patient from the age of 12 will also have HEADSS assessment so that by the time they get to 16 , hopefully we'll have fairly solid information about these people."

\section{Self-Management and Ownership}

In order to achieve a positive transition experience, young people need to begin to manage their own health and take ownership of aspects that may have previously been looked after by parents or carers such as medication and medical appointments. One of the driving factors behind the push to selfmanagement is the need to adhere to medicines. Transition is a period of concern with regard to medication nonadherence ${ }^{3}$ and both young people and professionals in the research project acknowledged this. Overall medication was one of the areas that young people noted as being addressed by their professional. One respondent recalled a conversation in which advice was given about organizing tablets:

Medication was one thing they did. I can remember then saying I should sort my tablets by putting them in doses and saying, that's Monday morning, that's Sunday night. So in terms of medication they did give me good prep.

Not all stories were as positive. A key point here appears to be that if young people are expected to take control of their medication, then they need to be the ones having the conversations with their professionals.

I had a period of rejection and I always remember people were talking to my mum saying, has she not been taking her tablets and nobody ever directed those questions at me, the person who does take the medication. Ultimately, I have the responsibility, my mum never force fed me my medication, but nobody ever asked me those questions.

\section{Using Mobile Technology}

Current NHS services offer telephone contact points for young people. However, services with transition nurses/coordinators or support workers do offer contact via SMS, although this has an impact on the workload of those involved. Young people and professionals welcomed the idea of a mobile phone application as a supportive tool. Young people noted that an app could provide transition information in an easily accessible location: "Even if there was brief explanations about what transition is, the transition team, and where they're located. So then you wouldn't have to spend your time trying to seek out the right people."

A phone app could be used as a gateway for contacts and both young people and professionals agreed contact details should be published. However, the issue of interaction via Internet forums accessed through the app needed greater consideration as one professional noted, such forums would need careful moderation to ensure they are not being abused.

Phone apps can be used to as repositories or a way of linking to information that is otherwise rather disparate and hard to navigate. In the United Kingdom, the CLDF have produced medically verified resources that are useful for young people. It was felt that giving young people access to such information 
was important and that the key was not to reinvent or rewrite good work but to provide better and more streamlined access to it. Young people felt that frequency asked questions (FAQs) would be helpful and an easy and quickly accessible resource: "It might be actually to have sort of FAQs and if you're having a problem, then you look on the information on the app then that's helpful."

Young people felt that as a result, a central repository for information would relieve some of the anxieties of asking questions during medical appointments. This was particularly noted by 1 young person who suggested that access to such information would be worthwhile as medical appointments tend to focus upon immediate concerns such as blood results.

I think it would also be good to highlight some areas that you never really thought about asking. So with the liver transplant Facebook group that I'm on, some people mentioned having skin problems because some of the side effects of the medicines makes you more prone to them and I never thought of asking that. I suppose they're just so busy worrying about your current issues, or blood results that they don't really think about other problems.

\section{Discussion}

Previous work has highlighted the importance of communication paths between young people and their health-care providers ${ }^{4}$ and suggests that before transition occurs, the young person needs to be comfortable communicating with new professionals and a system should be in place to facilitate such communication. Our research supports this and young people particularly noted the importance of dedicated persons, such as transition nurses/coordinators. However, our research found that it is often the communication paths between professionals that break down and cause most problems for young people. One example was provided where a young person's blood results were not sent to the relevant consultant at the hospital.

There is a growing body of work with regard to what knowledge/information is required in order to make a successful transition. Our research has suggested that young people do indeed welcome more knowledge about their care and their condition. Furthermore, in England, there is an understanding that transition should occur when young people are ready and not with regard to their age. Recent National Institute for Health and Care Excellence guidelines ${ }^{8}$ and the Ready Steady Go initiative ${ }^{9}$ clearly present this case. Our data however has suggested that in practice, this may not yet be occurring in England with young people describing their experiences as being dumped into adult services. The implication for practice of these findings suggest that young people wanted information about the transition process as early as possible (certainly earlier than they received) and be given clear, consistent messages in transition pathways.

Previous research ${ }^{5,13}$ has suggested that self-management needs to take place for the transition process to occur success- fully. Our research supports and furthered this with specific reference to the use of mobile phone applications. Young people and indeed professionals clearly felt that phone applications could be used to support transition by providing quick and easy access to information. It was felt that it could be useful to have the option to set reminders for medication and medical appointments, which have been shown in other populations to be of benefit and improve medication adherence. ${ }^{14}$ Smartphone technology also enables apps to access interactive features such as maps and forums and can provide young people with a method of contacting their professionals.

\section{Conclusion}

This article has shared the experiences of young liver patients in relation to transition and how mobile phone applications could potentially support the population. It adds to the important body of literature that has explored technology to support young people to transition, although liver patients remain an underresearched population as is reflected in the literature accessed here.

\section{Acknowledgments}

The authors expressed thanks to Children's Liver Disease Foundation (CLDF), United Kingdom, for their support of this study. 


\section{Declaration of Conflicting Interests}

The author(s) declared no potential conflicts of interest with respect to the research, authorship, and/or publication of this article.

Funding

The author(s) disclosed receipt of the following financial support for the research, authorship, and/or publication of this article: The project has been funded by the Children's Liver Disease Foundation (CLDF), United Kingdom.

References

1. Blum RW, Garell D, Hodgman CH, et al. Transition from child- centered to adult health-care systems for adolescents with chronic conditions: a position paper of the Society for Adolescent Medicine. J Adolesc Health. 1993;14(7):570-576.

2. Applebaum MA, Lawson EF, von Scheven E. Perception of transition readiness and preferences for use of technology in transition programs: teens' ideas for the future. Int J Adolesc Med Health. 2013;25(2):119125. doi:10.1515/ijamh-2013- 0019.

3. Berquist RK, Berquist WE, Esquivel CO, Cox KL, Wayman KI, Litt IF. Adolescent non-adherence: prevalence and conse- quences in liver transplant recipients. Pediatr Transplant. 2006;10(3):304-310.

4. Fredericks EM, Dore-Stites D, Lopez MJ, et al. Transition of pediatric liver transplant recipients to adult care: patient and parent perspectives. Pediatr Transplant. 2011;15(4):414-424. doi:10.1111/j.13993046.2011.01499.x.

5. Fredericks EM, Dore-Stites D, Well A, et al. Assessment of transition readiness skills and adherence in pediatric liver trans- plant recipients. Pediatr Transplant. 2010;14(8):944-953. doi: 10.1111/j.13993046.2010.01349.x.

6. NHS Choices. Liver transplant. Risks of a liver transplant. 2015. http://www.nhs.uk/conditions/Livertransplant/Pages/Introduc tion.aspx. Accessed October 28, 2017.

7. WebbN,HardenP,LewisC,etal.Buildingconsensusontransi- tion of transplant patients from paediatric to adult healthcare. Arch Dis Child. 2010;95(8):606-611. doi:10.1136/adc.2009. 176255.

8. National Institute for Health and Care Excellence. Transition from children's to adults' services for young people using health or social care services. 2016. https://www.nice.org.uk/guidance/ ng43. Accessed October 28, 2017.

9. Nagra A, McGinnity PM, Davis N, Salmon AP. Implementing transition: Ready Steady Go. Arch Dis Child Educ Pract Ed. 2015;100(6):313-320. doi:10.1136/archdischild-2014-307423.

10. Franklin VL, Waller A, Pagliari C, Greene SA. A randomized controlled trial of Sweet Talk, a text-messaging system to support young people with diabetes. Diabet Med. 2006;23(12):1332-1338.

11. Boyatzis RE. Transforming Qualitative Information: Thematic Analysis and Code Development. London, UK: Sage; 1998.

12. Goldenring JM, Cohen E. Getting into adolescent heads. Contemp Pediatr. 1988;5:75-90. http://contemporarypediatrics.mod ernmedicine.com/sites/default/files/images/Resource-Centers/ GettingintoTeensHeads.pdf. Accessed October 28, 2017.

13. Annunziato RA, Hogan B, Barton C, et al. A translational and systemic approach to transferring liver transplant recipients from pediatric to adult-oriented care settings. Pediatr Transplant. 2010;14(7):823829. doi:10.1111/j.1399-3046.2010. 01348.x.

14. Vollmer WM, Owen-Smith AA, Tom JO, et al. Improving adherence to cardiovascular disease medications with information technology. Am J Manag Care. 2014;20(11 spec no. 17): SP502-SP510. 